\title{
Teacher's Personality: Reflected by Responding to the Environmental Stimuli Instead of Reacting
}

\author{
C. Girija Navaneedhan \\ Rajalakshmi College of Education, Chennai, India \\ Email: girija60@rediffmail.com
}

Received 19 July 2014; revised 5 September 2014; accepted 6 October 2014

Copyright (C) 2014 by author and OALib.

This work is licensed under the Creative Commons Attribution International License (CC BY). http://creativecommons.org/licenses/by/4.0/

(c) (i) Open Access

\begin{abstract}
In psychological terms personality is defined as the particular combination of emotional, attitudinal, and behavioral response patterns of an individual. It is believed philosophically that the personality of an individual is determined by following factors namely: 1) freedom vs determinism, 2) heredity vs environment, 3) uniqueness vs universality, 4) activeness vs reactiveness, 5) optimism vs pessimism. The paper work focuses on finding how teacher's personality is reflected by being intuitive that is responding to the external stimuli rather than reacting to it. A survey was conducted on a group of $100 \mathrm{~B}$. Ed students in the age group of 23 to 40 years consisting of 60 females and 40 males. The personality determinant questionnaire prepared by $\mathrm{H}$. J. Eysenck consists of 86 questions with the possibility of choosing only one answer to each of the questions. The result of the study indicated that $70 \%$ of the total population showed extraversion and impulsive personality trait.
\end{abstract}

Keywords

Personality, Reflection, Characteristics, Respond

Subject Areas: Psychology, Sociology

\section{Introduction}

The term personality is very difficult to define as it involves measurement of the extent to which one is able to interest or influence other people. It is the sum total of the qualities of character, mind and body that make each individual unique. Successful teachers have numerous personality traits that make them good teachers; however, some traits seem to be common to all successful teachers. Chapel Hill, Dr. Paul Marchbanks determined that the traits of passion, patience, cooperation, authoritativeness and creativity were the essential personality traits of an 
effective elementary school teacher. This is a look at how those personality traits affect learning. Berry pointed out that students learn more about the characteristics of teachers [1]. Cruickshank, Jenkins \& Metcalf viewed that effective teachers are generally positive minded individuals who believe in their own ability by responding to the situation believing in the success of their students as well as to help students achieve [2]. Irvine suggested that teachers open to accept their mistakes forgiving tendencies; appreciating students' achievement enables the students to focus more on their learning activities [3]. Renzulli focused on teacher behavior suggesting on the personality characteristics in terms of knowledge, skills, professional attitudes, and teaching approaches and strategies [4]. A study conducted by Bishop on the characteristics of US school teachers revealed that teachers possessing some of the following characteristics namely [5]:

- maturity and experience;

- intellectual superiority;

- high achievement orientation;

- commitment to intellectual growth;

- favorable attitude toward students;

- orderly and systematic approach;

- imagination;

- engagement in intellectual pursuits

gain high regards from their students. Several research studies have mentioned that students recognize the qualities like honesty, creativity, understanding and patience in teachers. Lewis [6], Abel and Karnes [7] reported in their study conducted on primary students that teacher's helpfulness was valued. Benjamin Franklin well said that "if an individual empties his purse into his head, no one can take it from him". This saying is applicable to teachers as they should be capable of using their intellect which would eventually reflect on their personality. According to Beebe et al. [8], teacher's personality could be refined by adopting strategies such as thinking in broad sense about the situation that is pros and cons, handling the situation systematically, blending logic and emotion that is balancing those immediate emotional responses with thoughts and facts to fill in the blanks. This is the essence of responding to a situation-asking certain key questions to one's own self. Several research studies in the past suggested that teacher's quality of responding to the environment improves by consciously focusing attention on the speaker; noticing body language and non-verbal cues to allow for a richer understanding of the speaker's point; seeking an overall understanding of what the speaker is trying to communicate, rather than reacting to the individual words or terms that they use to express themselves; being empathetic to the feelings of the speaker; seeking additional information and observations; trying not to take everything personally; solving problems rather than attempting to control it (for example, not criticizing the work of students though it might not be accurate); allowing the students to express their ideas; being open to the ways of doing things. The following model highlights the important characteristics of how to respond to situation rather than reacting to it (Figure 1).

The model explains that the personality of the teacher is the reflection of all these characteristics and a teacher must possess in order to respond to the situation; all these characteristics are interlinked to one another.

\section{Objective of the Study}

To judge teacher's personality based on the response or reacting to situation.

$>$ To find the relationship between personality and the gender of the teachers.

$>$ To find whether there is any significant difference between male and female teachers in terms of personality.

\section{Hypotheses}

There is no significant difference between male and female teachers with reference to personality.

$>$ There is no significant relationship between male and female teachers with reference to extraversion and psychoticism, neuroticism dimensions of personality.

\section{Research Instrument}

Eysenck personality questionnaire consisting of 86 statements was given to the sample with yes/no option. The questionnaire consists of four categories determining extraversion, psychoticism, neuroticism and lie scale. 19 statements in extraversion, 20 statements in psychoticism, 23 statements in neuroticism and 24 statements in lie scale. 


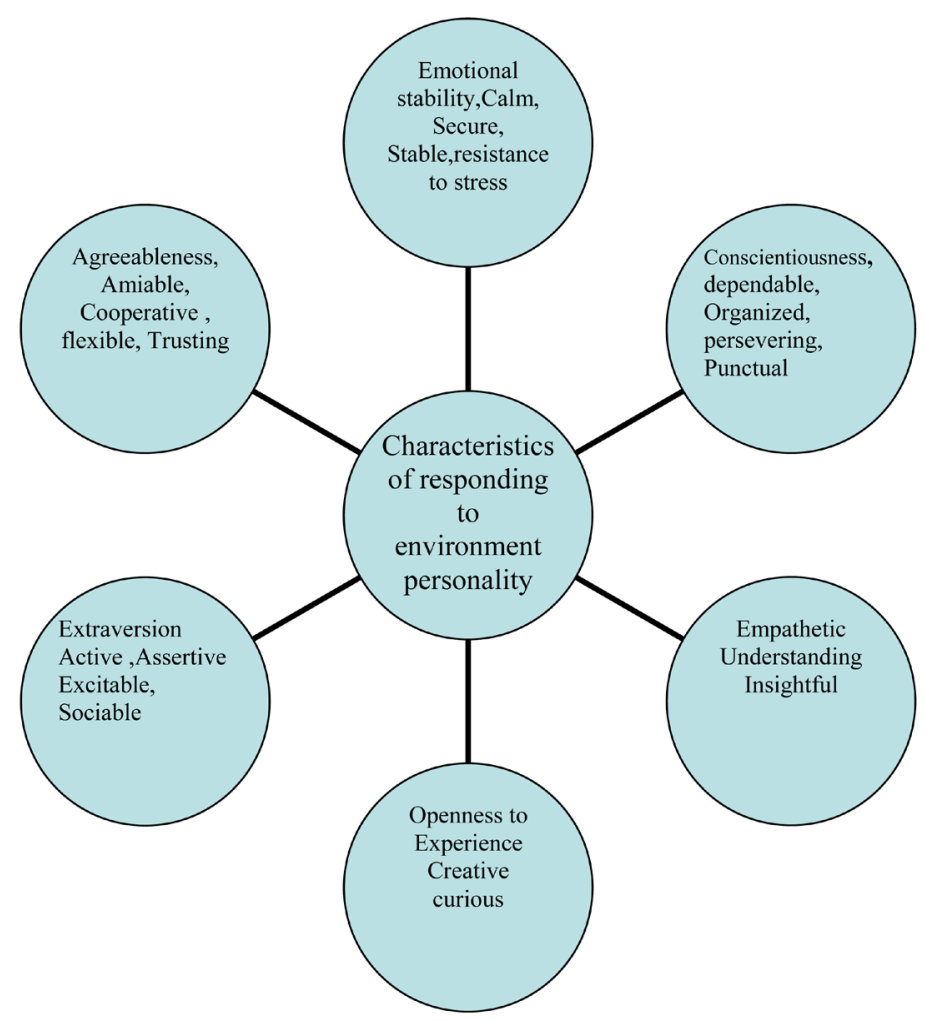

Figure 1. Teacher's response model to environmental stimuli.

\subsection{Sample}

Sample consists of 100 male and female teachers in the age group 23 to 40 years were selected for the study.

\subsection{Methodology}

A survey was conducted using Eysenck personality questionnaire as it deals with extraversion and psychoticism, neuroticism being the personality traits exhibited by reacting to environmental stimuli rather than responding it. The sample was asked to read each and every statement in the questionnaire carefully to tick yes or no option. Based on the response the scores obtained were subjected to statistical analysis. The results of the analysis are tabulated as follows.

\section{Findings}

From the Table 1 it is interpreted that there is no significant difference between male and female teachers with respect to personality showing that personality is independent of gender. Bodenhausen [9] predicted that the majority of the individuals adopted their own strategies to accommodate themselves in social circumstances irrespective of their gender.

The major finding from the statistical analysis is that there is no significant difference between male and female teachers with reference to overall personality and there is significant relationship between male and female teachers with reference to extraversion and psycho extraversion and psychoticism proving that the gender has no role to play. Teachers irrespective of their gender should respond to the environmental stimuli rather than reacting to it.

\section{Discussion}

From the Table 2 it is interpreted that in exhibiting extraversion and psychoticism, psychoticism and neuroticism male and female teachers showed significant relationship indicating that they differ in these traits significantly compared to extraversion neuroticism, extraversion and lie scale, psychoticism and lie scale as well as 
Table 1. To show the significant difference between male vs female teachers with respect to their personality.

\begin{tabular}{ccccc}
\hline Psychological variable & $\mathrm{N}$ & Gender & “t” & L.S \\
\hline \multirow{2}{*}{ Personality } & 60 & Females & \multirow{2}{*}{ N.S } & N.S \\
\hline
\end{tabular}

${ }^{*} \mathrm{P}<0.5,{ }^{* *} \mathrm{P}<0.01,{ }^{* * *} \mathrm{P}<0.001, \mathrm{~N} . \mathrm{S}=$ Not Significant.

Table 2. To show the relationship between extraversion and psychoticism, neuroticism, and lie scale with respect to gender.

\begin{tabular}{|c|c|c|c|c|}
\hline Psychological variable & $\mathrm{N}$ & Gender & “r” & L.S \\
\hline \multirow{2}{*}{ Extraversion and psychoticism } & 60 & Female & \multirow{2}{*}{$0.452^{* *}$} & \multirow{2}{*}{0.01} \\
\hline & 40 & Male & & \\
\hline \multirow{2}{*}{ Extraversion and neuroticism } & 60 & Female & \multirow{2}{*}{0.216} & \multirow{2}{*}{ N.S } \\
\hline & 40 & Male & & \\
\hline \multirow{2}{*}{ Psychoticism and neuroticism } & 60 & Female & \multirow{2}{*}{$0.512^{* *}$} & \multirow{2}{*}{0.01} \\
\hline & 40 & Male & & \\
\hline \multirow{2}{*}{ Extraversion and lie scale } & 60 & Female & \multirow{2}{*}{0.321} & \multirow{2}{*}{ N.S } \\
\hline & 40 & Male & & \\
\hline \multirow{2}{*}{ Psychoticism and lie scale } & 60 & Female & \multirow{2}{*}{0.255} & \multirow{2}{*}{ N.S } \\
\hline & 40 & Male & & \\
\hline \multirow{2}{*}{ Neuroticism and lie scale } & 60 & Female & \multirow{2}{*}{0.167} & \multirow{2}{*}{ N.S } \\
\hline & 40 & Male & & \\
\hline
\end{tabular}

${ }^{*} \mathrm{P}<0.5,{ }^{* * *} \mathrm{P}<0.01,{ }^{* * * *} \mathrm{P}<0.001, \mathrm{~N} . \mathrm{S}=$ Not Significant.

neuroticism and lie scale. In the combination of traits extraversion neuroticism, extraversion and lie scale, psychoticism and lie scale as well as neuroticism and lie scale male and female teachers do not differ much showing that responding to the situation not reacting purely depends only on individuals irrespective of the gender. Therefore male and female teacher should undergo self training in order to improve their personality by responding to the situation and reacting to it.

\section{Conclusion}

Teachers responding to the situation rather than reacting to the situation help to reflect upon their personality as it enables them to understand the students in the classroom. By repeated self direction one could develop sincerity, personal integrity, humility, courtesy, charity and wisdom being the essential qualities of a teacher. Similarly teachers developing the sense of responding to the situation focus upon academic success, respect for others, attentiveness, consideration, and cooperation, time management, responsibility, diligence, determination fairness, compassion, friendliness and loving nature. Finally it is concluded that teacher's character of being responding to situation not reacting forms a concrete foundation which would eventually reflect on their personality enabling them to become true professional helping them in making the learning process interesting and enjoyable.

\section{References}

[1] Berry, B. (2002) What It Means to Be a "Highly Qualified Teacher”. Southeast Center for Teaching Quality.

[2] Cruickshank, D.R., Jenkins, D.B. and Metcalf, K.K. (2003) The Act of Teaching. McGraw-Hill, New York.

[3] Irvine, J.J. (2001) Caring, Competent Teachers in Complex Classrooms. AACTE Publications, Washington DC.

[4] Renzulli, J.S. (1980) Will the Gifted Child Movement Be Alive and Well in 1990? Gifted Child Quarterly, 24, 3-9. http://dx.doi.org/10.1177/001698628002400102

[5] Bishop, W.E. (1980) Successful Teachers of the Gifted. In: Renzulli, J.S. and Stoddard, E.P., Eds., Under One Cover: Gifted and Talented Education in Perspective, Council for Exceptional Children, Reston, 152-160. 
[6] Lewis, J.F. (1982) Bulldozers or Chairs? Gifted Students Describe Their Ideal Teacher. The Gifted Child Today, 16-19.

[7] Abel, T. and Karnes, F.A. (1994) Teacher Preferences among the Lower Socioeconomic Rural and Suburban Advantaged Gifted Students. Roeper Review, 17, 52-57. http://dx.doi.org/10.1080/02783199409553619

[8] Beebe, et al. (2000) Interpersonal Communication: Relating to Others. 2nd Canadian Edition, Allyn and Bacon, Scarborough.

[9] Bodenhausen, G.V. (2007) Editorial. Personality and Social Psychology Review, 11, 3. http://dx.doi.org/10.1177/1088868306296187 